\title{
Persistent QEEG Abnormality in Crack Cocaine Users at 6 Months of Drug Abstinence
}

\author{
Kenneth R. Alper, M.D., Leslie S. Prichep, Ph.D., Sharon Kowalik, M.D., Ph.D., \\ Mitchell S. Rosenthal, M.D., and E. Roy John, Ph.D.
}

The major objective of this study was to examine the persistence of abnormal quantitative EEG ( $q E E G$ ) measures over a six month time interval in subjects in strictly supervised drug free residential treatment for crack cocaine dependence. Seventeen subjects were assessed with qEEG at five to 10 days, one month and six months following their last use of cocaine. No significant changes were noted over time in abnormal qEEG measures, which included deficits of absolute and relative power in the delta band and increased relative alpha power. The persistence of $q E E G$ abnormality in crack cocaine withdrawal suggests a persistent neurobiologic alteration resulting from chronic cocaine exposure. The specificity of the qEEG findings is discussed, and an interpretation is suggested with reference to the hypothesis of neural sensitization in cocaine dependence. [Neuropsychopharmacology 19:1-9, 1998] (C) 1998 American College of Neuropsychopharmacology. Published by Elsevier Science Inc.
KEY WORDS: Human; Crack cocaine; EEG, Delta EEG power; Drug abuse; Sensitization

Work performed in this laboratory and elsewhere indicates profile of quantitative EEG (qEEG) abnormality in crack cocaine dependence (Alper et al. 1990; Roemer et al. 1995; Prichep et al. 1996b). In subjects evaluated within 30 days of their last use of crack cocaine, consistent and statistically robust differences from normal subjects include reduced delta absolute and relative power, and increased alpha relative power. This question of whether this profile of qEEG abnormality per-

From the Brain Research Laboratories, Department of Psychiatry (KRA, LSP, SK, ERJ) and Comprehensive Epilepsy Center, Department of Neurology (KRA), New York University Medical Center, New York, NY, USA; Nathan S. Kline Institute for Psychiatric Research (LSP, ERJ), Orangeburg, NY, USA; and Phoenix House Foundation (MSR), New York, NY, USA.

Address correspondence to: Kenneth R. Alper, M.D., Brain Research Laboratories, Department of Psychiatry, NYU Medical Center, Old Bellevue Admin. Bldg., 8th Floor, 462 First Avenue, New York, NY 10016.

Received April 15, 1996; revised March 18, 1997; accepted November 10, 1997. sists over longer intervals of abstinence is of interest for several reasons. Sensitization due to repeated psychostimulant exposure, which is suggested to be an etiologic factor in cocaine dependence, persists with a time frame of months to years (Kalivas et al. 1993a; Grace 1995; Johanson and Schuster 1995). Also, in the therapeutic community (TC), a long term drug free residential treatment environment, the minimum time of retention required to produce statistical evidence of benefit with regard to outcome is reportedly on the order of three to six months (DeLeon 1991; Condelli and Hubbard 1994). It is of interest whether the qEEG abnormality, seen at baseline, persists or begins to normalize over a time period apparently associated with clinical change.

In the present study we report on the persistence of qEEG abnormality in subjects with cocaine dependence evaluated sequentially at five to 10 days, one month and six months after their last use of cocaine. The major objectives of this report are to present the data regarding change in qEEG measures over an extended interval of abstinence, and to attempt to interpret the findings with respect to current literature on cocaine sensitization and the physiologic generation of the EEG. 


\section{METHODS}

\section{Subjects}

Subjects were recruited from consecutive admissions to Phoenix House Foundation's Induction Facility in the Bronx, New York City. Phoenix House is a large drugfree TC, with multiple sites in the Northeastern U.S. and California. At Phoenix House, all clients first spend 30 days in the Induction Facility prior to placement at one of the TC sites in the greater metropolitan New York area.

Psychiatric and neuropsychological evaluations were performed to select subjects meeting the following Inclusion/Exclusion criteria: 1) Fulfilling DSM-III-R criteria for cocaine dependence for at least one year and self report of strongly preferring crack cocaine to any other substance; 2) No history of ever having met DSMIII-R criteria for dependence on any substance other than cocaine and alcohol; 3) Alcohol intake limited to non-dependence levels in the year preceding admission; 4) Negative urine screening for other drugs including heroin, barbiturates, amphetamine, and phencyclidine; 5) No history of head trauma with loss of consciousness, or significant neurologic medical condition including any history of seizures regardless of association with drug abuse; 6) No history of IV drug use; 7) No clinical evidence of HIV infection or self-report of a positive HIV antibody test; 8) No history of psychotropic medication treatment within 60 days of intake; 9) IQs within the normal/low normal range (estimated IQs $\geqslant 80)$; 10) No current involvement with the justice or corrections system. This last criteria was adopted in order to control for an effect of legal pressure when studying retention as a dependent variable (Prichep et al. 1996a).

Each patient was interviewed by a psychiatrist utilizing the Structured Clinical Interview for DSM-III-R (Spitzer et al. 1990). The presence of depression and/or anxiety was rated by the psychiatrist using the Hamilton Depression Scale (Hamilton 1980) and Hamilton Anxiety Scale (Hamilton 1959), and also rated using the self-administered Beck Depression Inventory (Beck et al. 1961) and Beck Anxiety Inventory (Beck et al. 1988). Cocaine craving was evaluated with the Minnesota Cocaine Craving Scale (Halikas et al. 1991).

The demographic and drug use history characteristics of the study populations are summarized in Table 1. Subjects were tested initially at five to 10 days after the last reported use of cocaine, and subsequently after at least one month, and again after six months of continuous residential treatment at Phoenix House. Phoenix House clients typically spend their first 30 days in program at the Induction Facility and are subsequently transferred to outlying residential sites. All Phoenix House facilities, including both Induction and the outlying residential sites, are locked. Electrophysiologic testing was conducted at the Induction Facility. Subjects tested later in their stay at Phoenix House were transported from their residential site to Induction accompanied by Phoenix House staff. In screening subjects for participation in the study, drug use histories, including the day of last use prior to entry into treatment,were elicited in the absence of the subjects knowledge of the implication of his or her answer regarding study participation. Subjects reported at mean time interval of 3.2 $( \pm 2.4)$ days between their last use of cocaine and entry into treatment.

\section{EEG Data Acquisition}

The patients were seated comfortably in a light attenuated room, while 20 minutes of eyes closed resting EEG data were collected from the 19 monopolar electrode sites of the International 10/20 system, referred to linked earlobes. A differential eye channel was used for the detection of eye movement. All electrode imped-

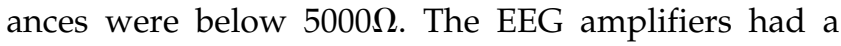
bandpass from 0.5 to $70 \mathrm{~Hz}$ ( $3 \mathrm{~dB}$ points), with a $60 \mathrm{~Hz}$ notch filter. Data were sampled at $200 \mathrm{~Hz}$ with 12 bit resolution.

\section{qEEG Data Analysis}

Two minutes of artifact-free data were extracted from the EEG record for quantitative analysis. A computerized artifact-detection algorithm combined with visual inspection was used to obtain 48 epochs $(2.5 \mathrm{sec}$ each, for a total of $2 \mathrm{~min}$ ) of artifact-free data from $20 \mathrm{~min}$ of continuous EEG. Power spectral analysis was performed using Fast Fourier Transform (FFT). For each of the 19 monopolar derivations, absolute and relative (\%) power, mean frequency, interhemispheric coherence, and asymmetry were computed for the delta (1.5-3.5 $\mathrm{Hz})$, theta $(3.5-7.5 \mathrm{~Hz})$, alpha $(7.5-12.5 \mathrm{~Hz})$, and beta (12.5-25 Hz) frequency bands. Monopolar coherence and asymmetry were computed relating each paired

Table 1. Demographic and Clinical Characteristics for the Group of 17 Subjects; Psychiatric Rating Instrument Scores were Obtained at the First EEG Session

\begin{tabular}{lc}
\hline Gender & 12 male, 5 female \\
Age & $34.3 \pm 7.9$ years \\
Ethnicity & 15 African American \\
& 2 Hispanic \\
Age first used crack or cocaine & $26.7 \pm 8.0$ years \\
Years of crack use & $6.2 \pm 2.5$ years \\
Previous year crack use & $4.1 \pm 6.1 \mathrm{~g} / \mathrm{wk}$ \\
Minnesota Cocaine Craving Scale score & $3.9 \pm 3.6$ \\
Beck Depression Inventory score & $14.6 \pm 11.1$ \\
Hamilton Depression Scale score & $12.3 \pm 5.4$ \\
Beck Anxiety Inventory score & $5.6 \pm 5.2$ \\
Hamilton Anxiety Scale score & $9.0 \pm 8.2$ \\
\hline
\end{tabular}


10/20 lead with its counterpart on the opposite hemisphere, i.e., F3 and F4, etc. The univariate asymmetry and coherence measure sets consist of 8 left-right electrode pairs in each bandwidth. The convention in Neurometrics is that the left side is the numerator and the right side the denominator in computing ratios for asymmetry measures, so that a positive value denotes left greater than right asymmetry. Using Neurometrics, all quantitative features are log transformed to obtain Gaussianity, age-regressed, and Z-transformed relative to population norms. The importance of each of these steps in enhancing the sensitivity and specificity of electrophysiological data has been discussed in detail elsewhere (John et al. 1988), as is test-retest reliability (Kaye et al. 1981; John et al. 1983; Fein et al. 1984). Independent replications have confirmed the Neurometric qEEG norms (Matousěk and Petersén 1973; Gasser et al. 1982; Jonkman et al. 1985; Alvarez et al. 1987; Harmony et al. 1987; John et al. 1989). Z transformed data, scaled in the metric of probability as standard deviation units, is displayed as color coded topographic maps.

The Hotelling $\mathrm{T}^{2}$ test (BMDP 3D) was used to assess the significance of interval change between the baseline, 1 month and 6 month sessions. The degrees of freedom for the Hotelling $\mathrm{T}^{2}$ comparisons are 19 and 14 for the 19 monopolar lead locations for absolute and relative power, and 8 and 25 for the 8 electrode pairs for asymmetry and coherence. The Levene F for variability test was used to evaluate the potential confound of differential variability between the underlying univariate mea- sures comprising the sets being compared by the Hotelling $\mathrm{T}^{2}$ at baseline, one month and six months.

\section{RESULTS}

Table 2 lists the results of the between sessions Hotelling $\mathrm{T}^{2}$ comparisons for baseline versus one month and six months, and one month versus six months. No significant change is seen for EEG absolute and relative power, asymmetry and coherence in any frequency bandwidth for any of the sessions. Figure 1 presents topographic maps of the set of univariate measures for the 19 EEG electrode locations for relative and absolute spectral power obtained at baseline, 1 month and 6 months. The similarity of the images emphasizes the lack of change of the qEEG measures over the period of the study. The qEEG profile is abnormal with regard to reduced relative and absolute power in delta, and, to a lesser extent, theta. The reader is referred elsewhere for more detailed description of this qEEG profile (Alper et al. 1990; Prichep et al. 1996b; Roemer et al. 1995).

Table 3 lists the relative frequency of Levene $\mathrm{F}$ for variability test results significant at the $p \leqslant .05$ level for each of the sets of univariate measures comparing the Hotelling $\mathrm{T}^{2}$ comparisons in Table 2. The overall frequency of significant results is 0.0062, which does not exceed the rate expected on the basis of chance alone. The results suggests that the apparent lack of change in the EEG indicated by the Hotelling $\mathrm{T}^{2}$ comparisons is

Table 2. Results of Hotelling $\mathrm{T}^{2}$ for Intersession Changes in $\mathrm{qEEG}$ Measures

\begin{tabular}{|c|c|c|c|c|c|c|c|c|}
\hline & \multicolumn{2}{|c|}{ Abs. Power } & \multicolumn{2}{|c|}{ Rel. Power } & \multicolumn{2}{|c|}{ Asymmetry } & \multicolumn{2}{|c|}{ Coherence } \\
\hline & $\mathbf{T}^{2}$ & $p \geqslant$ & $\mathbf{T}^{2}$ & $p \geqslant$ & $\mathbf{T}^{2}$ & $p \geqslant$ & $\mathbf{T}^{2}$ & $p \geqslant$ \\
\hline \multicolumn{9}{|l|}{$\Delta$} \\
\hline BL vs. 1 mo. & 40.91 & .63 & 37.52 & .69 & 11.31 & .41 & 2.17 & .98 \\
\hline BL vs. 6 mos. & 63.63 & .31 & 59.02 & .36 & 4.38 & .90 & 8.69 & .63 \\
\hline 1 mo vs. 6 mos. & 19.44 & .96 & 63.14 & .31 & 4.15 & .91 & 6.62 & .63 \\
\hline \multicolumn{9}{|l|}{$\Theta$} \\
\hline BL vs. 1 mo. & 61.71 & .33 & 79.05 & .18 & 5.35 & .83 & 7.06 & .71 \\
\hline BL vs. 6 mos. & 58.93 & .36 & 88.22 & .14 & 4.16 & .91 & 7.25 & .69 \\
\hline 1 mo. vs. 6 mos. & 18.76 & .97 & 13.48 & .99 & 4.75 & .87 & 9.30 & .54 \\
\hline \multicolumn{9}{|l|}{$\alpha$} \\
\hline BL vs. 1 mo. & 40.72 & .53 & 42.27 & .60 & 6.73 & .73 & 1.39 & .99 \\
\hline BL vs. 6 mos. & 38.74 & .56 & 103.74 & .08 & 13.40 & .30 & 6.89 & .72 \\
\hline 1 mo. vs. 6 mos. & 35.12 & .84 & 25.18 & .91 & 10.30 & .47 & 8.69 & .58 \\
\hline \multicolumn{9}{|l|}{ 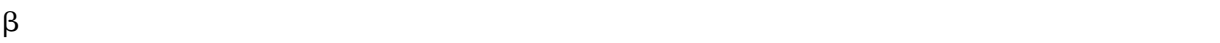 } \\
\hline BL vs. 1 mo. & 80.12 & .18 & 20.94 & .94 & 6.79 & .73 & 6.62 & .74 \\
\hline BL vs. 6 mos. & 11.28 & .99 & 35.34 & .73 & 2.83 & .97 & 5.05 & .86 \\
\hline 1 mo. vs. 6 mos. & 25.23 & .89 & 26.56 & .88 & 10.45 & .46 & 9.33 & .55 \\
\hline
\end{tabular}

"BL vs. 1 Mao.", and "BL vs. 6 mo." refer to the comparison at baseline versus 1 and 6 months respectively, and " 1 mo. vs. 6 mo." refers to the comparison at 1 month versus 6 months. Comparisons involve absolute and relative power for each of the 19 standard 10/20 lead locations, and monopolar interhemispheric coherence and asymmetry for 8 left-right electrode pairs. Comparisons are computed for each of the 4 EEG bandwidths indicated at the left of the table. No results are significant, indicating the persistence of the abnormal qEEG pattern over the 6 month interval of observation. 


\section{Topographic Maps of QEEG Features in}

\section{Crack Cocaine Dependent Adults}

\section{During 3 Intervals of Abstinence}

\section{Baseline (5-10 Days of Abstinence)}

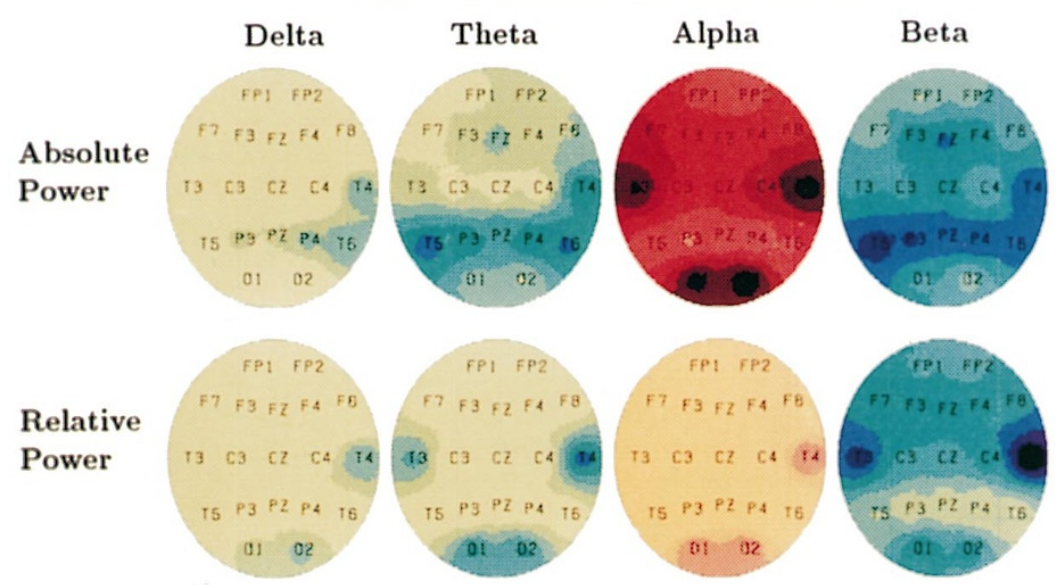

\section{Month of Abstinence}

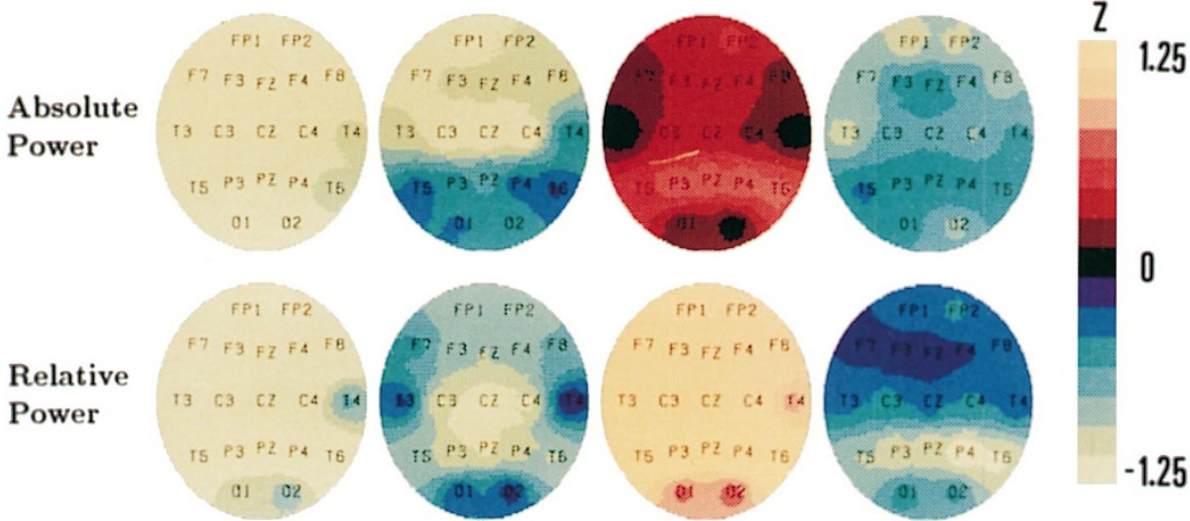

\section{Months of Abstinence}

Absolute

Power
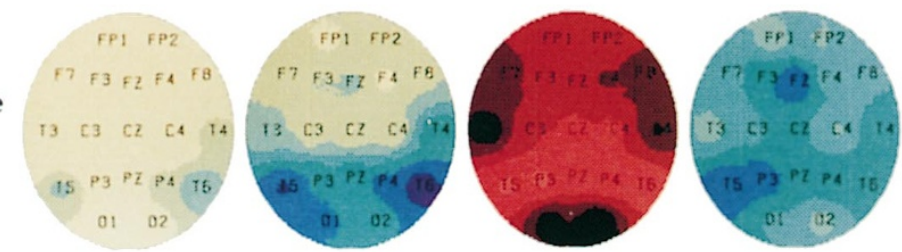

Relative Power
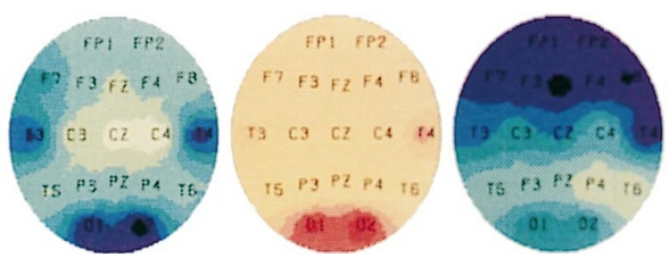

Figure 1. Absolute and relative spectral power in 17 subjects tested at baseline at 5-10 days following their use of cocaine prior to entry, and then subsequently at 1 and 6 months of strictly supervised drug free residential treatment. The relative lack of change is evident in the similarity of the 3 sets of images. 
not on the basis of differential variability across time of the underlying univariate EEG measures.

\section{DISCUSSION}

The qEEG profile initially reported in a sample of 7 subjects (Alper et al. 1990) has now been replicated in two subsequent independent studies involving 90 and 52 patients (Roemer et al. 1995; Prichep et al. 1996b). In this present study, we report on the persistence of the abnormal qEEG profile in subjects followed longitudinally into 6 months of abstinence.

With regard to other substance use disorders that are frequently comorbid with crack cocaine dependence, the qEEG findings of this study do not resemble qEEG profiles reported for alcohol dependence in which alpha power is reportedly decreased and theta increased (Alper 1995), or cannabis dependence in which slow EEG power is not reportedly decreased (Struve et al. 1989, 1994). qEEG data on heroin dependence is scant. However, reported histories of dependence on heroin or intravenous drug assumption (IVDA) were exclusion criteria and positively affirming crack cocaine as a drug of choice was an inclusion criteria, which tended to mitigate against a potential confound of opiate dependence. Crack cocaine is a reported risk factor for human immunodeficiency virus (HIV), another confound related to drug abuse (Booth et al. 1993). Abnormal qEEG has been reported in HIV seropositive patients (Riedel et al. 1995), however a reported history of HIV seropos- itivity, or constitutional signs of HIV was an exclusion criterion in this study. The New York City Department of Health has been conducting a large blind HIV seroprevalance study at Phoenix House since 1993 (Lehner et al. 1995) involving 1482 clients to date, and reports an overall seroprevalance of only $7.6 \%$, probably due to the relatively low prevalence of a history of intravenous drug abuse in the Phoenix House population. In any event, the qEEG findings reported here do not resemble those of early HIV infection in which slow frequency EEG power is reportedly increased (Riedel et al. 1995).

The correlation of the EEG with length of exposure to cocaine also offers a measure of evidence for a specific effect of cocaine. In the present sample, increased theta mean frequency and decreased alpha mean frequency showed the strongest correlations with estimated cumulative exposure to cocaine (Prichep et al. 1996c). Roemer et al. (1995) did not report on mean frequency but did report some qEEG correlations with lifetime cocaine exposure that were also found in this present study. In both the present study and that of Roemer et al. (1995), reduced delta coherence and abnormalities of beta asymmetry were correlated with length of exposure to cocaine. Like Roemer et al. (1995) we found fewer correlations of the qEEG with alcohol or cannabis exposure than cocaine exposure. The strongest correlation in the domain of alcohol exposure was increased theta power correlating with an earlier age of onset of alcohol use.

Given the evidence that this persistently abnormal qEEG pattern is replicable and appears to relate to cocaine exposure, the question arises as to how the EEG

Table 3. Stability of Variance of Univariate Measures Over Time

\begin{tabular}{|c|c|c|c|c|}
\hline & Abs. Power & Rel. Power & Asymmetry & Coherence \\
\hline \multicolumn{5}{|l|}{$\Delta$} \\
\hline BL vs. 1 mo. & $0 / 19$ & $0 / 19$ & $0 / 8$ & $0 / 8$ \\
\hline BL vs. 6 mos. & $0 / 19$ & $0 / 19$ & $0 / 8$ & $0 / 8$ \\
\hline 1 mo. vs. 6 mos. & $0 / 19$ & $0 / 19$ & $0 / 8$ & $0 / 8$ \\
\hline \multicolumn{5}{|l|}{$\Theta$} \\
\hline BL vs. 1 mo. & $0 / 19$ & $0 / 19$ & $0 / 8$ & $0 / 8$ \\
\hline BL vs. 6 mos. & $0 / 19$ & $0 / 19$ & $0 / 8$ & $0 / 8$ \\
\hline 1 mo. vs. 6 mos. & $0 / 19$ & $0 / 19$ & $0 / 8$ & $0 / 8$ \\
\hline \multicolumn{5}{|l|}{$\alpha$} \\
\hline BL vs. 1 mo. & $0 / 19$ & $0 / 19$ & $0 / 8$ & $0 / 8$ \\
\hline BL vs. 6 mos. & $0 / 19$ & $0 / 19$ & $0 / 8$ & $0 / 8$ \\
\hline 1 mo. vs. 6 mos. & $0 / 19$ & $0 / 19$ & $0 / 8$ & $0 / 8$ \\
\hline \multicolumn{5}{|l|}{$\beta$} \\
\hline BL vs. 1 mo. & $1 / 19$ & $0 / 19$ & $1 / 8$ & $0 / 8$ \\
\hline BL vs. 6 mos. & $0 / 19$ & $0 / 19$ & $0 / 8$ & $0 / 8$ \\
\hline 1 mo. vs. 6 mos. & $0 / 19$ & $0 / 19$ & $0 / 8$ & $1 / 8$ \\
\hline
\end{tabular}

Proportion of Levene F for variability results significant at the $p \leqslant .05$ level for sets of either 19 individual or 8 pairs of monopolar EEG leads for each of the Hotelling $\mathrm{T}^{2}$ comparisons from Table 2. The Levene Test addresses the issue of whether the variance of the underlying univariate measures differs between Hotelling comparisons. Significant Levene F results occurred at an overall rate of 0.0062 which does not exceed the rate of 0.05 expected on the basis of chance. This result suggests that the lack of interval change reflected in the Hotelling comparison is not due to the potential confound of unequal variance between sets of univariate measures. 
might relate to the neurophysiology of the waking delta EEG rythym and the neurobiology of cocaine dependence. A relationship of the EEG to the neurobiology of cocaine might be expected on the basis of the evidence that the EEG is a physiologically relevant summation of neural activity (Nũnez 1995; Freeman and Barrie 1994; Steriade et al. 1990).

The most statistically robust $\mathrm{qEEG}$ finding in cocaine dependence on which we or Roemer et al. (1995) have reported has been a deficit of delta power (Prichep et al. 1996b; Alper et al. 1990). The conventional EEG literature greatly emphasizes delta excesses in neurologic illness but provides little discussion of the significance of a deficit of delta. However, multiply replicated adult norms indicate that 20 to $30 \%$ of the total EEG power in central and anterior leads in awake humans is in the delta frequency band (Matousěk and Petersén 1973; Gasser et al. 1982; Jonkman et al. 1985; Alvarez et al. 1987; Harmony et al. 1987; John et al. 1989) and there is a substantial qEEG literature relating delta power to higher order mental functions in normal awake humans. Increased delta activity has been observed in normal subjects performing calculations (Fernandez et al. 1995), reaction time tasks (Van Dijk et al. 1992), abstract thought (Michel et al. 1993), or an omitted stimulus paradigm (Basar-Eroglu et al. 1992), and to covary positively with P300 amplitude (Basar et al. 1984; Intriligator and Polich 1994). A functional role has been suggested for delta in facilitating "inner concentration" by suppressing extraneous cortical inputs in order to maximize the allocation of attention to tasks involving internal representation (Fernandez et al. 1995). A delta deficit could be a correlate of reduced frontal cortical regulation or gating of responses to maladaptive behavioral impulses or extraneous cues. In this regard it is interesting that the other groups in our database that show a delta deficit; namely attention deficit disorder (Chabot and Serfontein 1996), and subtypes of obsessive compulsive disorder (Prichep et al. 1993) and schizophrenia (John et al. 1994), appear to have notable problems with frontal cortical regulation of attention or impulsive behavior, and the gating of preattentive or extraneous stimuli.

There is evidence to suggest a significant functional relationship of the delta rhythm to the mesotelencephalic dopamine (DA) projection, and hence to the neurobiology of cocaine. Studies utilizing dipole modeling (Michel et al. 1992, 1993) and the correlation of positron emission tomography and the EEG (Alper et al. 1994, 1998) estimate the location of the major site of delta generation in midline and anterior frontal cortex, which corresponds with the location of the main cortical terminal field of the mesotelencephalic DA projection. Cortical layer $\mathrm{V}$ contains the pyramidal cells that are thought to generate the delta rhythm (McCormick 1992; Steriade et al. 1990), as well as high density of DA ter- minals whose synaptic architecture and laminar distribution appear specifically adapted to the horizontal integration necessary to modulate the wide field, global delta rhythm (Berger 1994; Silberstein 1995). Selectively enhanced transmission of oscillatory activity at certain frequencies, or "resonance" is determined to a significant extent by the frequency of underlying single unit activity of neurons comprising the resonant neural structure (Steriade et al. 1990; Creutzfeldt et al. 1993; Freeman and Barrie 1994). Single unit activity in the delta range has been recorded directly from the nucleus accumbens (Leung and Yim 1993), frontal cortex (Steriade et al., 1993a, b, c) and the VTA (Grace 1995). The observation that $\mathrm{DA}$ related behaviors are selectively enhanced by stimulation of DA cell axons at $2-3 \mathrm{~Hz}$ (Grace 1995) is also consistent with resonance in the delta frequency band in the mesotelencephalic DA projection.

The observation that stimulation or DA administration to the VTA desynchronizes slow EEG activity (Rougeul-Buser 1994) might be consistent with a hypothesis of sensitized VTA DA activity in cocaine dependence as an explanation for the observed decrease in delta EEG power. Sensitization is currently an influential hypothesis of the neurobiology of cocaine dependence (Johanson and Schuster 1995). With repeated administration of cocaine or other stimulants, DA neurons in the VTA acquire a pattern of relatively increased or "sensitized" responsiveness to cocaine as well as other activating stimuli such as stress, corticosterone or "priming" doses of rewarding substances (Kalivas et al. 1993b; Kiyatkin 1995; Grace 1995). Although cocaine sensitization has not been explicitly demonstrated in humans, the model is supported by a substantial body of animal work, and a number of respected researchers have published papers attempting to link the clinical features of cocaine dependence to a hypothesis of cocaine sensitization (Robinson and Berridge 1993; Grace 1995; Kalivas et al. 1993b). The sensitization model may be pertinent to the persistent nature of the qEEG findings because sensitization appears to persist over a time frame of months to years, unlike other reported charges in DA transmission that resolve within days or weeks of cocaine abstinence (Grace 1995; Johanson and Schuster 1995). Human EEG studies cannot directly measure cocaine sensitization, however, the model is useful as a heuristic framework for generating testable qEEG hypotheses. Negative D.C. shifts occur in humans in expectant behavioral states analogous to states reportedly associated with increased VTA activity in animals (Caspers 1993; Haschke et al. 1993; Kiyatkin 1995). According to a sensitization hypothesis, the electrophysiologic response to corticosteroid challenge, stress, drug related stimuli, or "priming" doses of DA agonists should be relatively greater in cocaine dependence than in normal controls and might, therefore, be expected to produce greater relative D.C. shifts from baseline. Pharmaco-EEG investi- 
gations involving dopaminergic, noradrenergic, or serotonergic agonists or antagonists in normal controls and subjects with cocaine dependence might be informative regarding the relationship of altered activity of these neuromodulators to the qEEG.

We have reported elsewhere on initial findings of an apparent relationship of baseline EEG to subsequent retention in treatment (Prichep et al. 1996a, c). If substantiated, this finding is significant validating evidence as it correlates the EEG with a cardinal clinical feature of cocaine dependence, the tendency to resume use after days or weeks of abstinence. Beta activity, which is seen with VTA activation (Rougeul-Buser 1994) was predictive of treatment failure in our work on cocaine dependence (Prichep et al. 1996a, c), as well as another study on alcohol dependence (Bauer 1993). Given the relative lack of predictive ability of sociodemographic data, psychiatric rating scales or measures of reported self reported craving (Bauer 1992; DeLeon 1991), a relationship of the EEG to retention in treatment suggests the possibility that the EEG may indeed access preattentive determinants of behavior not available to conscious introspection.

Animal work could provide an approach to obtaining controlled longitudinal observations over the time interval corresponding to initiation and maintenance of cocaine self administration. This may prove to be important as qEEG changes seen acutely following a dose of cocaine to relatively infrequent cocaine users may differ from the persistent abnormal findings we have observed with chronic users. Herning et al. (1985) studied a population of relatively infrequent, "recreational" cocaine users noted increased delta power at 5 minutes after an intravenous dose of cocaine. A population of heavier, more experienced users in a later study showed no delta increase (Herning et al. 1994). These results are consistent with a model in which the development of cocaine sensitization due to chronic exposure results in progressive diminution of EEG delta power. Longitudinal observations of animals self administering cocaine involving EEG or unit activity recorded from the cortex, anterior striatum, ventral pallidum, and VTA might be potentially informative regarding the possible relationship of delta EEG power to the early encoding of drug salience or the later expression of sensitization. Such work, combined with human pharmaco-EEG studies, might provide an approach to understanding the pathophysiologic basis for the abnormal, and apparently relatively persistent qEEG profile associated with cocaine dependence which we and others have observed.

\section{ACKNOWLEDGMENTS}

This work was supported by National Institute of Drug Abuse RO1 DA07707-03. The authors also wish to gratefully ac- knowledge the contribution of Henry Merkin, MeeLee Tom, Larisa Vaysblat and the Phoenix House staff to this research.

\section{REFERENCES}

Alper K (1995): Quantitative EEG and evoked potentials in adult psychiatry. In Panksepp J (ed), Advances in Biological Psychiatry, Vol. 1. Greenwich, Connecticut, JAI Press, pp 65-112

Alper K, Günther W, Prichep LS, John ER, Brodie J (1998): Correlation of qEEG with PET in Schizophrenia. Neuropsychobiology, in press

Alper K, John ER, Brodie J, Prichep LS, Günther W, Daruwala R (1994): Correlation of qEEG and PET in schizophrenics and normals. In Maurer K, Taneli B (eds), Third International Symposium Imaging of the Brain in Psychiatry and Related Fields: Program and Abstracts, Antalya, Turkey. Frankfurt, International Society for Neuroimaging in Psychiatry, pp 80-81

Alper KR, Chabot RJ, Kim AH, Prichep LS, John ER (1990): Quantitative EEG correlates of crack cocaine dependence. Psychiatry Res 35:95-106

Alvarez A, Pascual R, Valdes P (1987): U.S. EEG developmental equations confirmed for Cuban schoolchildren. EEC Clin Neurophysiol 67:330-332

Basar E, Basar-Eroglu C, Rosen B, Schutt A (1984): A new approach to endogenous event related potentials in man: Relation between EEG and P300 wave. Intl J Neurosci 26:161-180

Basar-Eroglu C, Basar E, Demiralp T, Schurmann M (1992): P300-response: possible psychophysiological correlates in delta and theta frequency channels. A review. Intl J Psychophysiol 13:161-179

Bauer LO (1992): Psychobiology of craving. In Lowinson JH, Ruiz P (eds), Substance Abuse: A Comprehensive Textbook, Chapter 5. Baltimore, Williams \& Wilkins, pp 51-55

Bauer LO (1993): Motoric signs of CNS dysfunction associated with alcohol and cocaine withdrawal. Psychiatry Res 47:69-77

Beck AT, Brown G, Epstein N, Steer RA (1988): An inventory for measuring clinical anxiety: Psychometric properties. J Consult Clin Psychol 56:893-897

Beck AT, Ward CH, Mendelson M, Mock JE, Erbaugh J (1961): An inventory for measuring depression. Arch Gen Psychiatry 4:561-571

Berger B (1994): Distinctive chemoanatomical and developmental features of the prefrontal dopaminergic system in primates as compared to rodents. In Thierry A-M, Glowinski J, Goldman-Rakic PS, Christen Y (eds), Motor and Cognitive Functions of the Prefrontal Cortex. Berlin, Heidelberg, Springer-Verlag, pp 17-34

Booth RE, Watters JK, Chitwood DD (1993): HIV risk-related sex behaviors among injection drug users, crack smokers, and injection drug users who smoke crack. Am J Public Health 83(8):1144-1148

Caspers H (1993): DC potentials of the brain. In Haschke W, Speckman EJ, Roitbak AI (eds), Slow Potential Changes in the Brain, Chapter 1. Boston, Birkhauser, pp 9-20

Chabot RJ, and Serfontein G (1996): Quantitative EEG pro- 
files of children with Attention Deficit Disorder. Biol Psychiatry 40:951-963

Condelli WS, Hubbard RL (1994): Relationship between time spent in treatment and client outcomes from therapeutic communities. J Substance Abuse Treat 11(1):25-33

Creutzfeldt OD, Ojemann GA, Chatrian GE (1993): Activity of single neurons and their relationship to normal EEG waves and interictal epilepsy potentials in humans. In Haschke W, Speckman EJ, Roitbak AI (eds), Slow Potential Changes in the Brain, Chapter 2. Boston, Birkhauser, pp 21-42

DeLeon G (1991): Retention in drug-free therapeutic communities. In Pickens $\mathrm{R}$, Leukfeld C, Schuster CR (eds), Improving Drug Abuse Treatment: Research Monograph 106. Washington, D.C., USGPO, pp 218-244

Fein G, Galin D, Yingling CD, Johnstone J, Nelson MA (1984): EEG spectra in 9 13-year-old boys are stable over 1-3 years. EEG Clin Neurophysiol 58:517-518

Fernandez T, Harmony T, Rodriguez M, Bernal J, Silva J, Reyes A, Marosi E (1995): EEG activation patterns during the performance of tasks involving different components of mental calculation. EEG Clin Neurophysiol 94:175-182

Freeman WJ, Barrie JM (1994): Chaotic oscillations and the genesis of meaning in cerebral cortex. In Buzsaki GL, Llinas R, Singer W, Bertroz A, Christen Y (eds), Temporal Coding in the Brain. Berlin, Springer Verlag, pp 13-38

Gasser T, Bacher P, Mochs J (1982): Transformation towards the normal distribution of broadband spectral parameters of the EEG. EEC Clin Neurophysiol 53:119-124

Grace AA (1995): The tonic/phasic model of dopamine system regulation: Its relevance for understanding how stimulant abuse can alter basal ganglia function. Drug Alcohol Depend 37:111-129

Halikas JA, Kuhn KL, Crosby R, Carlson G, Crea F (1991): The measurements of craving in cocaine patients using the Minnesota Cocaine Craving Scale. Comp Psychiatry $32: 22-27$

Hamilton M (1959): The assessment of anxiety states by rating. Br J Med Psychol 32:50-55

Hamilton M (1980): Rating depressive patients. J Clin Psychiatry 41:21-24

Harmony T, Alvarez A, Pascual R, Ramos A, Marosi E, Diaz De Leon AE, Valdes P, Becker J (1987): EEG maturation of children with different economic and psychosocial characteristics. Intl J Neurosci 31:103-113

Haschke R, Tennigkeit M, Lehmann HJ, Haschke W (1993): Changes of slow brain potential shifts following failure. In Haschke W, Speckman EJ, Roitbak AI (eds), Slow Potential Changes in the Brain, Chapter 4. Boston, Birkhauser, pp 63-84

Herning RI, Jones RT, Hooker WD, Mendelson J, Blackwell L (1985): Cocaine increases EEG beta: A replication and extension of Hans Berger's historic experiments. EEG Clin Neurophysiol 60:470-477

Herning RI, Glover BJ, Koeppl B, Phillips RL, London ED (1994): Cocaine-induced increases in EEG alpha and beta activity: Evidence for reduced cortical processing. Neuropsychopharmacology 11(1):1-9
Intriligator J, Polich J (1994): On the relationship between background EEG and the P300 event-related potential. Biol Psychiatry 37:207-218

Johanson C, Schuster CR (1995): Cocaine. In Bloom FE, Kupfer DJ (eds), Psychopharmacology: The Fourth Generation of Progress, Chapter 145. New York, Raven Press, pp 1685-1697

John ER, Prichep LS, Ahn H, Easton P, Fridman J, Kaye H (1983): Neurometric evaluation of cognitive dysfunctions and neurological disorders in children. Progress Neurobiol 21:239-290

John ER, Prichep LS, Ahn H, Kaye H, Brown D, Easton P, Karmel BZ, Toro A, Thatcher R (1989): Neurometric Evaluation of Brain Function in Normal and Learning Disabled Children. Ann Arbor, Univ. of Michigan Press

John ER, Prichep LS, Alper KR, Mas FG, Cancro R, Easton P, Sverdlov L (1994): Quantitative electrophysiological characteristics and subtyping of schizophrenia. Biol Psychiatry 36:801-826

John ER, Prichep LS, Friedman J, Essig-Peppard T (1988): Neurometric classification of patients with different psychiatric disorders. In Samson-Dollfus D (ed), Statistics and Topography in Quantitative EEG. Paris, Elsevier, pp 88-95

Jonkman EJ, Poortvliet DCJ, Veering MM, deWeerd AW, John ER (1985): The use of neurometrics in the study of patients with cerebral ischemia. EEG Clin Neurophysiol 61:333-341

Kalivas PW, Churchhill L, Klitenick MA (1993a): The circuity mediating the translation motor responses motivational stimuli into adaptive motor responses. In Kalivas PW, Barnes CD (eds), Limbic Motor Circuits and Neuropsychiatry. Boca Raton, CRC Press, pp 239-309

Kalivas PW, Sorg BA, Hooks MS (1993b): The pharmacology and neural circuitry of sensitization to psychostimulants. Behav Pharmacol 4:315-334

Kaye H, John ER, Ahn H, Prichep LS (1981): Neurometric evaluation of learning disabled children. Intl J Neurosci 13:15-25

Kiyatkin EA (1995): Functional significance of mesolimbic dopamine. Neurosci Biobehav Revs 19(4):578-598

Lehner T, Torian L, Alper K, Geringer W, Horton T, Gonzalez I, Weisfuse I (1995): HIV infection among non-injecting drug users entering a drug treatment facility in New York City. Abstracts, 35th Interscience Conference Antimicrobial Agents and Chemotherapy, San Francisco, CA, p 7

Leung LS, Yim CY (1993): Rythmic delta-frequency activities in the nucleus accumbens of anesthetized and freely moving rats. Can J Physiol Pharmacol 71:311-320

Matousěk M, Petersén I (1973): Norms for the EEG. In Kellaway P, Petersén I (eds), Automation of Clinical Electroencephalography. New York, Raven, pp 75-102

McCormick DA (1992): Neurotransmitter actions in the thalamus and cerebral cortex and their role in neuromodulation of thalamocortical activity. Prog Neurobiol 39: 337-388

Michel AM, Lehmann D, Henggeler B, Brandeis D (1992) Localization of the sources EEG delta, theta, alpha and beta frequency bands using the FFT dipole approximation. EEG Clin Neurophysiol 82:38-44 
Michel AM, Henggeler B, Brandeis D, Lehmann D (1993): Localization of sources of brain alpha/theta/delta activity and the influence of the mode of spontaneous mentation. Physiol Meas 14:21-26

Nũnez PL (1995): Experimental connections between EEG data and the global wave theory. In Nũnez PL (ed), Neocortical Dynamics and Human EEG Rhythms. New York, Oxford University Press, pp 534-590

Prichep L, Alper K, Kowalik SC, Rosenthal MS (1996a): Neurometric qEEG studies of crack cocaine dependence and treatment outcome. J Addictive Diseases 15(4):39-53

Prichep LS, Alper KR, Kowalik SC, John ER, Merkin HA, Tom M, Rosenthal MS (1996b): Quantitative electroencephalographic characteristics of crack cocaine dependence. Biol Psychiat 40(10):986-993

Prichep LS, Alper KR, Kowalik SC, John ER, Merkin HA, Tom M, Rosenthal MS (1996c): qEEG subtypes in crack cocaine dependence and treatment outcome. In Harris LS (ed), Problems of Drug Dependence, 1995: Proceedings of 57th Annual Scientific Meeting, The College on Problems of Drug Dependence, Inc., Research Monograph No. 162. Rockville, MD, National Institute on Drug Abuse, p 142

Prichep LS, Mas F, Hollander E, Liebowitz M, John ER, Almas M, DeCaria CM, Levine RH (1993): Quantitative electroencephalographic (qEEG) subtyping of obsessive compulsive disorder. Psychiatry Res 50(1):25-32

Riedel R, Alper KR, Bulau P, Niese D, Schieck U, Günther W (1995): qEEG in hemophiliacs with HIV infection. Clin EEG 26:84-91

Robinson TE, Berridge KC (1993): The neural basis of drug craving: An incentive-sensitization theory of addiction. Brain Res Revs 18:247-291

Roemer RA, Cornwall A, Dewart D, Jackson P, Ercegovac DV (1995): Quantitative electroencephalographic analysis in cocaine-preferring polysubstance abusers during abstinence. Psychiatry Res 58:247-257

Rougeul-Buser A (1994): Electrocortical rhythms in the $40 \mathrm{hz}$ band in cat: In search of their behavioral correlates. In
Buzsaki G, Llinas R, Singer W, Berthoz A, Christen Y (eds), Temporal Coding in the Brain. Berlin, SpringerVerlag, pp 103-114

Silberstein RB (1995): Neuromodualtion and neocortical dynamics. In Nũnez P (ed), Neocortical Dynamics and Human EEG Rhythms, Chapter 13. New York, Oxford University Press, pp 591-627

Spitzer RL, Williams JBW, Gibbon M, First MB (1990): Structured Clinical Interview for DSM-III-R-Patient Edition (SCID-P, Version 1.0). Washington, DC, American Psychiatric Press.

Steriade M, Gloor P, Llinas RR, Lopes da Silva F, Mesulam MM (1990): Basic mechanisms of cerebral rythmic activities. EEG Clin Neurophysiol 76:481-508

Steriade M, Nuñez A, Amzica F (1993a): Intracellular analysis of relations between the slow $(<1 \mathrm{~Hz})$ neocortical oscillation and other sleep rhythms of the electroencephalogram. J Neurosci 13(8):3266-3283

Steriade M, Nuñez A, Amzica F (1993b): A novel slow $(<1$ $\mathrm{Hz}$ ) oscillation of neocortical neurons in vivo: Depolarizing and hyperpolarizing components. J Neurosci 13(8):3252-3265

Steriade M, Nuñez A, Amzica F (1993c): The slow (<1 Hz) oscillation in reticular thalamic and thalamocortical neurons: Scenario of sleep rhythm generation in interacting thalamic and neocortical networks. J Neurosci 13(8):3284-3299

Struve FA, Straumanis JJ, Patrick G (1994): Persistent topographic quantitative EEG sequelae of chronic marihuana use: A replication study and initial discriminant function analysis. Clin EEG 25(2):63-75

Struve FA, Straumanis JJ, Patrick G, Price L (1989): Topographic mapping of quantitative EEG variables in chronic heavy marijuana users: Empirical findings with psychiatric patients. Clin EEG 20(1):6-23

Van Dijk JG, Caekebeke J, Schinkel AJ, Zwinderman AH (1992): Background EEG reactivity in auditory eventrelated potentials. EEG Clin Neurophysiol 83:44-51 